\title{
Minimizing Products Rates Variation in Just-in-Time Mixed-Model Manufacturing
}

\author{
Ghorbanali Mohammadi1 ${ }^{*}$, Darius Mohammadi2 \\ ${ }^{1}$ Department of Industrial Engineering, College of Engineering, Qom University of Technology, Qom, Iran \\ ${ }^{2}$ Electrical and Computer Engineering Department, College of Engineering, lowa State University, Ames, IA, USA \\ Email: "ghorbanalim@yahoo.co.uk, Dariusm@iastate.edu
}

Received 7 December 2015; accepted 6 March 2016; published 9 March 2016

Copyright (C) 2016 by authors and Scientific Research Publishing Inc.

This work is licensed under the Creative Commons Attribution International License (CC BY).

http://creativecommons.org/licenses/by/4.0/

cc) (i) Open Access

\begin{abstract}
Mixed-Model assembly lines are often used in manufacturing based on just-in-time techniques. The effective utilization of these lines requires a schedule for assembling the different models be determined. The objective is to minimize the total deviation of actual production rates from the desired production rates. Mathematical method with the optimization algorithm is proposed here to solve this problem. To prove the efficiency of the proposed algorithm, a number of test problems are solved. The results show that the proposed algorithm is an efficient and effective algorithm which gives better results with the large problem sizes. This paper presents a practical procedure to minimize total product variation rates, and easy to use by practitioner.
\end{abstract}

\section{Keywords}

\section{Mixed-Model Assembly Lines, JIT, Scheduling, Optimization, Manufacturing}

\section{Introduction}

Mixed-Model assembly lines mainly used due to the following advantages: They provide a continuous flow of materials, reduce the inventory levels of final items, and very flexible with respect to model changes [1]. However, this flexibility requires expensive equipment, which reduces or even eliminates delays due to set-up activities ([2] chapter, 6). The Just-in-time (JIT) production system has been well known worldwide for achieving high efficiency. Just-in-time was originally developed by Toyota Motor Company in Japan to respond to various changes of circumstance such as fluctuating demand and diversified products [3]. To deal with frequent changes in demand and increasing variety in models, producing mixed-models on an assembly line become widely adopted in the manufacturing industry around the world to achieve flexibility and smooth part usage rates. The

\footnotetext{
${ }^{*}$ Corresponding author.
} 
effective utilization of these lines requires the following problems be solved [4]:

1) Determination of line cycle time;

2) Determination of the number and sequence of stations on the line;

3) Line balancing;

4) Determination of the sequence schedule for producing different products on the line.

The sequence of introducing models to the mixed-model assembly lines is different due to the different goal or purposes of controlling the line. In sequencing mixed-model assembly lines, two goals are commonly considered.

1) Levelling the workloads (total assembly time) among all stations within the Line (goal chasing 1). This goal smoothes out the workload on the final assembly line to reduce the line inefficiencies described as idleness, work deficiency, utility work and work congestion. (See, for example, [5]-[8].)

2) Keeping a constant rate of usage for every part used by the line (goal chasing 2). This is called "balancing" or levelling the schedule by [9] [10]. For most of the industrial applications, determining an optimal balanced schedule is a very difficult combinatorial problem [11]. This goal should be to schedule models on the mixedmodel final assembly line in such a way that production of each model is synchronized with the demand for that model. Sequencing models that go along a production or assembly line, with the objective of attenuating the variations in the rates of resource consumption is a problem that has received growing attention during last years. The SA approach presented by author previous work [12] can handle both goals for smoothing the workload. Kubiak [13] has defined that as the objective of the product rate variation (PRV) problem, which is the minimization of variation in the production rate of different final models produced on the final assembly line. Kubiak and Sethi [14] have shown that the product rate variation problem can be reduced to an assignment problem that can be solved efficiently, for example, Balas et al.'s [15] algorithm. Miltenburg et al. [16] proposes a dynamic programming algorithm to the product rate variation problem. Inman and Bulfin [17] propose the EDD approach for the Product rate variation problem with the objective function of minimizing the sum of both squared earliness and tardiness. Defining the time when $j$ th unit of model $i$ is needed-due-date-as $t_{i k}=\left[\left(K-\frac{1}{2}\right) D_{T}\right] / d_{i}$ and considering each unit of a model as a separate job, the sequencing problem is treated as a single-machine scheduling problem with earliness and tardiness objective. The optimal sequences are found by ordering the jobs following the EDD rule. Ding and Cheng's algorithm is another approach for the product rate variation problem. Ding and Cheng, [18] [19] propose a procedure to minimize the next-two-stage ( $k$ and $k+1)$ total squared deviation when a unit of a model is selected at a stage $k$. The problem also presented by Sumichrast and Russel [20], and Yeomans [21], and Bautista, [22], among others.

The plan of this paper is as follows. Product rate variation described in Section 2. In Section 3 practical Solution algorithm is presented. Mathematical procedure conducted in Section 4.

\section{The Product Rate Variation Problem (PRV)}

The PRV problem can be stated as follows: one has to produce $d_{i}$ units of each one of the $D_{T}$ models of a product with $\sum_{i=1}^{D_{T}} d_{i}=U$; the production system is flexible that is, it adapt to the production of any model in a negligible time. This PRV problem can be formulated as a non-linear integer-programming problem as follows (Miltenburg [9]; Kubiak [13]).

\section{Notation}

$n$ number of models or products types. $d_{i}$ demand for models, $d_{1}, d_{2}, \cdots, d_{n} . k$ number of stages per unit time period, $k=1,2, \cdots, D_{T} . D_{T}$ total model demand (units of models to be produced), $D_{T}=\sum_{i=1}^{n} d_{i} . F$ number of times that minimal part set is repeated. $i$ index, model to be produced, $\mathrm{i}=1,2, \ldots, \mathrm{n} . r_{i}$ production ratio, the proportion of model i demand to the total model demand, $r_{i}=\frac{d_{i}}{D_{T}} . \quad x_{i, k}$ total cumulative production of model i in period 1 through $k$. Where $k=1,2, \cdots, D_{T}$ 


\section{Mathematical Model}

Assume that there are $\mathrm{n}$ models to be produced within the planning horizon with demands $d_{1}, d_{2}, \cdots, d_{n}$, for a total demand of units. An implied time horizon of time units can be inferred, where one unit of model $i, i=1$, $2, \ldots, n$, will be produced in each time period. If $r_{i}=\frac{d_{i}}{D_{T}}$ then the level scheduling objective is to keep the total production per time period as close to $\mathrm{r}$ as possible, i.e., ideally, units of model $i$ should be produced in the first $\mathrm{k}$ time period $\left(k=1,2, \cdots, D_{T}\right)$.

Let, $x_{i, k} I=1,2, n, k=1,2, D_{T}$ be the total production of product $i$ in time periods 1 through $k$. Then the model can be written as:

$$
\begin{aligned}
& \text { (PRV) Minimize } Z=F \sum_{k=1}^{D_{T}} \sum_{i=1}^{n}\left(x_{i, k}-K_{r, i}\right)^{2} \\
& \text { ST } \\
& \sum_{i=1}^{n} x_{i, k}=K \quad k=1,2, \cdots, D_{T} \\
& 0 \leq x_{i, k}-x_{i, k-1} \leq 1 \quad \text { for } \quad i=1,2, \cdots, n ; \quad k=1,2, \cdots, D_{T} \\
& x_{i, k} \text { is non-negative intneger } \forall_{k}, \forall_{i}
\end{aligned}
$$

Constraint (1) ensures that exactly k units are scheduled in period 1 through k. Constraints (2) and (3) ensure that, for each model, either one unit is scheduled in a given period or else it is not scheduled at all. Define the point $X_{k}=\left(x_{1, k}, x_{2, k}, \cdots, x_{n, k}\right) \in R^{n}$ where $x_{i, k}=K r_{i} \sum_{i=1}^{n} x_{i, k}=K$, and $\mathrm{R}$ is the set of real numbers. Our objective is to find minimum product variation rates. Minimizing variation means: $\min \sum_{i=1}^{n}\left(x_{i, k}-K r_{i}\right)^{2}$. An optimal solution to product rate variation can be constructed from any optimal solution of the following assignment problem [17] [18].

$$
\begin{aligned}
& \text { Minimize } \sum_{k=1}^{D_{T}} \sum_{(i, j) \in I} C_{j k}^{i} X_{j k}^{i} \\
& \text { subject to } \\
& \sum_{(i, j) \in I} X_{j k}^{i}=1, \quad k=1,2, \cdots, D_{T} \\
& \sum_{k=1}^{D_{T}} X_{j k}^{i}=1, \quad(i, J) \in I \\
& X_{j k}^{i}=0 \text { or } k=1,2, \cdots, D_{T} ; \quad(i, J 0 \in I)
\end{aligned}
$$

The optimal schedule for the PRV is to order the jobs following the EDD rule [21].

$$
\begin{aligned}
& \text { Minimize } \sum_{i=1}^{n} \sum_{k=1}^{D_{T}}\left(Y_{i k}-t_{i k}\right)^{2} \\
& \text { s.t. } \\
& Y_{i, k+1} \geq Y_{i, k}+1, i=1, \cdots, n, \quad k=1, \cdots, D_{T-1} \\
& 1 \leq Y_{i, k} \leq D_{T} \quad i=1, \cdots, n, \quad k=1, \cdots, D_{T} \\
& Y_{i, k} \neq Y_{i, k} \\
& Y_{i, k} \text { is a non-negative integer }
\end{aligned}
$$

\section{Algorithm}

Step 1. Set $k=1$ and Set $X_{i, 0}=0$ for all $i$ 
Step 2. Among the $n$ models, schedule the models with smaller $x_{i, k-1}-(K+0.5) r_{i}$ (Break ties arbitrary). Step 3. Schedule all $x_{i, k}$ 's for all models.

If $k=D_{T}$ stop, this is the lowest objective function value, otherwise, $k=k+1$, go to step 2 .

At step 2, models with lowest $x_{i, k-1}-(K+0.5) r_{i}$ value have higher priority to be selected at stage $k$.

\section{Computational Procedure}

To compare Miltenburg Algorithm 3 with heuristic 1 with this practical procedure, we take example 3 conducted by Miltenburg [9]. The schedule suggested by MA3H1 was 1-2-3-4-5-1-2-3-4-6 for 10 stages in that example with the total variation 9.953 .

In our procedure the schedule is 1-2-3-4-1-2-3-4-5-6 with total variation of 8.1488 , this solution is optimal and much better than MA3H1 (see Table 1).

Example 3. There are $\mathrm{n}=7$ models with demands $\quad d_{1}=d_{2}=d_{3}=d_{4}=25$ and $d_{5}=d_{6}=d_{7}=4$

Hence $r_{1}=r_{2}=r_{3}=r_{4}=25 / 112$ and $r_{5}=r_{6}=r_{7}=4 / 112$

\begin{tabular}{ccccccccc}
\hline & \multicolumn{2}{c}{ Stage k } & & \multicolumn{3}{c}{$X_{k}=\left(x_{1}, x_{2}, \cdots, x_{7}\right)$} \\
\hline 1 & 0.223 & 0.223 & 0.223 & 0.223 & 0.036 & 0.036 & 0.036 \\
2 & 0.446 & 0.446 & 0.446 & 0.446 & 0.072 & 0.072 & 0.072 \\
3 & 0.670 & 0.670 & 0.670 & 0.670 & 0.107 & 0.107 & 0.107 \\
4 & 0.893 & 0.893 & 0.893 & 0.893 & 0.143 & 0.143 & 0.143 \\
5 & 1.116 & 1.116 & 1.116 & 1.116 & 0.179 & 0.179 & 0.179 \\
6 & 1.339 & 1.339 & 1.339 & 1.339 & 0.214 & 0.214 & 0.214 \\
7 & 1.563 & 1.563 & 1.563 & 1.563 & 0.250 & 0.250 & 0.250 \\
8 & 1.786 & 1.786 & 1.786 & 1.786 & 0.286 & 0.286 & 0.286 \\
9 & 2.009 & 2.009 & 2.009 & 2.009 & 0.321 & 0.321 & 0.321 \\
10 & 2.232 & 2.232 & 2.232 & 2.232 & 0.357 & 0.357 & 0.35 \\
\hline
\end{tabular}

Table 1. Example problem.

\begin{tabular}{|c|c|c|c|c|c|c|c|c|c|c|}
\hline \multirow{2}{*}{ stage } & \multicolumn{7}{|c|}{ Product } & \multirow{3}{*}{$\begin{array}{l}\text { Scheduled } \\
\text { product }\end{array}$} & \multirow{3}{*}{ Variation } & \multirow{3}{*}{$\begin{array}{c}\text { Total } \\
\text { Variation }\end{array}$} \\
\hline & 1 & 2 & 3 & 4 & 5 & 6 & 7 & & & \\
\hline $\mathrm{K}$ & \multicolumn{7}{|c|}{$x_{i, k-1}-(K+0.5) r_{i}$} & & & \\
\hline 1 & -0.335 & -0.335 & -0.335 & -0.335 & -0.054 & -0.054 & -0.045 & 1 & 0.787 & 0.787 \\
\hline 2 & 0.442 & -0.558 & -0.558 & -0.558 & -0.089 & -0.089 & -0.089 & $1-2$ & 1.038 & 1.825 \\
\hline 3 & 0.442 & -0.558 & -0.558 & -0.558 & -0.089 & -0.089 & -0.089 & $1-2-3$ & 0.802 & 2.627 \\
\hline 4 & 0.004 & -0.004 & -0.004 & -1.004 & -0.161 & -0.161 & -0.161 & $1-2-3-4$ & 0.0778 & 2.7048 \\
\hline 5 & -0.228 & -0.228 & -0.228 & -0.228 & -0.196 & -0.196 & -0.196 & $1-2-3-4-1$ & 0.87 & 3.5748 \\
\hline 6 & 0.549 & -0.451 & -0.451 & -0.451 & -0.232 & -0.232 & -0.232 & $1-2-3-4-1-2$ & 1.17 & 4.7448 \\
\hline 7 & 0.326 & 0.326 & -0.674 & -0.674 & -0.268 & -0.268 & -0.268 & $1-2-3-4-1-2-3$ & 0.99 & 5.7348 \\
\hline 8 & 0.103 & 0.103 & 0.103 & -0.897 & -0.304 & -0.304 & -0.304 & $1-2-3-4-1-2-3-4$ & 0.320 & 6.0588 \\
\hline 9 & -0.121 & -0.121 & -0.121 & -0.121 & -0.339 & -0.339 & -0.339 & $1-2-3-4-1-2-3-4-5$ & 0.726 & 6.7808 \\
\hline 10 & 0.334 & -0.344 & -0.344 & -0.344 & 0.625 & -0.375 & -0.375 & $1-2-3-4-1-2-3-4-5-6$ & 1.368 & 8.1488 \\
\hline
\end{tabular}




\section{Schedule Large Problems}

For scheduling large problem we take minimal part set of demand and repeated to the frequency of demand. A minimal part set will be defined as the smallest possible set as parts in the same proportion as the demands mix during the whole working period. Suppose if the model A, B, and C have the demand of 700, 200, and 100 units, respectively, it is difficult to sequence a total of 1000 or more work-piece at one time. This demand set $\{700$, $200,100\}$ is divided by its largest common divisor (which is 100 in this case) to obtain the minimal part set a $\{7$, $2,1\}$. The problem of scheduling all products during the working period is then reduced to finding the assigned order of models to stations in minimum part set $\{7,2,1\}$ order. The numbers of times that a minimal part set repeat in order to complete the demand during the entire working period is the largest divisor, called frequency, F. In this case is $F=100$. Motivation for working with the minimum part set is as follows: First, it is becoming common practice in industry to plan for production in terms of the minimum part set, especially in flexible manufacturing. Second, the approach greatly simplifies the computations, thereby permitting the derivation of optimal solution for problems of realistic size. Third, the results obtained from working with the minimum part set MPS rather than the full part are surprisingly better [23] [24]. It was stated by the Miltenburg [13] that a good assembly line sequencing algorithm should generate sequences made up of many repeating basic sequences.

\section{References}

[1] Kilbridge, M.D. and Wester, L. (1963) The Assembly Line Model-Mix Sequencing Problem. Proceeding of the third international conference operational Researches, English Universities Press (Paris: Dunod Editeur).

[2] Schonberger, R. (1982) Japanese Manufacturing Techniques-Nine Hidden Lessons in Simplicity. Free Press, New York.

[3] Ohno, T. (1986) The Origin of Toyota Production System and Kanban System. In: Monden, Y., Ed., Applying Just in Time: The American/Japanese Experience, Institute of Industrial Engineers Press, Nocross, GA.

[4] Okamura, K. and Yamashina H. (1979) A Heuristic Algorithm for the Assembly Line Model-Mix Sequencing Problem to Minimize the Risk of Stopping the Conveyor. International Journal of Production Research, 17, 233-247. http://dx.doi.org/10.1080/00207547908919611

[5] Yano, C.A. and Bolat, A. (1989) Survey, Development, and Application of Algorithms for Sequencing Paced Assembly Lines. Journal of Manufacturing Operations Management, 2, 172-198.

[6] Yano, C.A. and Rachamadugu, R. (1991) Sequencing to Minimize Work Overload in Assembly Lines with Product Options. Management Science, 37, 572-586.

[7] Xiaobo, Z. and Ohno, K. (1997) Algorithms for Sequencing Mixed-Models on an Assembly Lines in a Just-in-Time Production System. Computers and Industrial Engineering Journal, 32, 47-56.

[8] Xiaobo, Z. and Ohno, K. (1994) A Sequencing Problem for a Mixed-Model Assembly Line in a Just-in-Time Production System. Computers and Industrial Engineering Journal, 27, 71-74. http://dx.doi.org/10.1016/0360-8352(94)90240-2

[9] Miltenburg, G.J. (1998) Level Schedules for Mixed-Model Assembly Lines in Just-in-Time Production System. Management Science, 35, 192-207. http://dx.doi.org/10.1287/mnsc.35.2.192

[10] Miltenburg, G.J. and Sinnmon, G. (1989) Scheduling Mixed-Model Multi-Level JIT Production Systems. International Journal of Production Research, 27, 1487-1509. http://dx.doi.org/10.1080/00207548908942636

[11] Steiner, G. and Yeomans, S. (1991) Optimal Level Schedules for Mixed-Model, Just in Time. Working Paper, Faculty of Business, McMaster University, Hamilton.

[12] Mohammadi, G. (2011) Multi-Objective Simulated Annealing Algorithms for Scheduling Just-in-Time Assembly Lines. World Applied Science Journal, 13, 1916-1926.

[13] Kubiak, W. (1993) Minimizing Variation of Production Rates in Just-in-Time Systems: A Survey. European Journal of Operational Research, 66, 259-271. http://dx.doi.org/10.1016/0377-2217(93)90215-9

[14] Kubiak, W. and Sethi, S. (1991) Level Schedules for Mixed-Model Assembly Lines in Just-in-Time Production Systems. Management Science, 37, 121-122. http://dx.doi.org/10.1287/mnsc.37.1.121

[15] Balas, E., Miller, D., Pekny, J. and Toth, P. (1991) A Parallel Shortest Augment Path Algorithm for the Assignment Problem. Journal of the Association for Computing Machinery, 38, 985-1004. http://dx.doi.org/10.1145/115234.115349,

[16] Miltenburg, J., Steiner, G. and Yeomans, S. (1990) A Dynamic Programming Algorithm for Scheduling Mixed-Model Just-in-Time Production Systems. Mathematical and Computer Modeling, 13, 57-66. http://dx.doi.org/10.1016/0895-7177(90)90370-3 
[17] Inman, R.R. and Bulfin, R.L. (1991) Sequencing Just-in-Time Mixed-Model Assembly Lines. Management Science, 37, 901-904.

[18] Ding, F.Y. and Cheng, L. (1993) A Simple Sequencing Algorithm for Mixed-Model Assembly Lines in Just-in-Time Production Systems. Operations Research Letters, 13, 27-36. http://dx.doi.org/10.1016/0167-6377(93)90081-Q

[19] Ding, F.Y. and Cheng, L. (1993) An Effective Mixed-Model Assembly Line Sequencing Heuristic for Just-in-Time Production Systems. Journal of Operations Management, 11, 45-50. http://dx.doi.org/10.1016/0272-6963(93)90032-K

[20] Sumichrast, R.T. and Russel, R.S. (1990) Evaluating Mixed-Model Assembly Line Sequencing Heuristics for Just-inTime Production Systems. Journal of operations Management, 9, 371-390. http://dx.doi.org/10.1016/0272-6963(90)90161-6

[21] Yeoman, J.S. (1994) A Comment on “A Simple Sequencing Algorithm for Mixed Model Assembly Line in Just-inTime Production Systems”. Operations Research Letters, 16, 299-301. http://dx.doi.org/10.1016/0167-6377(94)90044-2

[22] Bautista, J. and Cano, J. (2007) Minimizing Work Overload in Mixed-Model Assembly Lines. International Journal of Production Economics, 112, 177-191.

[23] Thomopoulos, N.T. (1967) Line Balancing Sequencing for Mixed-Model Assembly. Management Science, 233 , 59-75. http://dx.doi.org/10.1287/mnsc.14.2.B59

[24] Dar-El, E.M. and Cother, R.F. (1975) Assembly Line Sequencing for Model-Mix. International Journal of Production Research, 13, 463-477. http://dx.doi.org/10.1080/00207547508943016 